\title{
INVENTARISASI ANGGREK HUTAN DI TAMAN WISATA ALAM BATUPUTIH, KOTA BITUNG, SULAWESI UTARA
}

\section{FOREST INVENTORY IN THE NATURAL TOURISM OF BATUPUTIH, CITY BITUNG, NORTH SULAWESI}

\author{
Amansyo Yubu'), Hard N. Pollo2), dan Marthen T. Lasut ${ }^{2)}$ \\ 1)Mahasiswa Program Studi IImu Kehutanan, Jurusan Budidaya Pertanian, Fakultas Pertanian Unsrat Manado, \\ 95115 \\ 2)Dosen Program Studi IImu Kehutanan, Jurusan Budidaya Pertanian, Fakultas Pertanian Unsrat Manado, 95115
}

\begin{abstract}
Orchid is the largest family that occupies $7-10 \%$ of flowering plants and has around 20,000 to 35,000 species. In Sulawesi, according to experts there are around 5000 species of plants that are not known with certainty about their spread and abundance. It has been estimated that approximately 253 endemic orchid species, around $80 \%$ of the total number of orchids. In the life stage, tropical orchid plants are epiphytic, with the root system attached to the tree, but does not harm the host tree. There are also those that grow geofitis, with other terms terresterial means to grow on the ground with roots in the soil. There are also those that are saprophytic, grow on the media of dried leaves and weathered wood that has rot into humus. To inventory forest species in Batuputih Nature Park, Bitung City, North Sulawesi. The study was conducted in January - February 2018. Data collection was carried out by exploratory methods. The types of orchids that were found during exploration in TWA Batuputih, which are sorted by the type most found on the three transects: namely Dendrodium sp with a total of 12 points at a height of 40-200 masl, Phaleonopsis amabilis with a height of $52-102$ masl as many as 3 points while, Dendrodium indivisum with a number of 1 point, which is at an altitude of 136 masl, Nervilia aragoana as many as 10 points with an altitude of 10-84 masl, and Nervilia plicata found only 1 point, at an altitude of 52 masl. Of the five types consisted of 3 genera, namely Dendrodium, Phaleonopsis, and Nervilia, and 2 types of (habitats) terrestrial and epiphytes.
\end{abstract}

Keywords: orchid, type and habitat of forest orchids

\begin{abstract}
ABSTRAK
Anggrek merupakan famili terbesar yang menempati 7-10\% tumbuhan berbunga dan memiliki sekitar 20.000 sampai 35.000 jenis. Di Sulawesi, menurut para ahli terdapat sekitar 5000 spesies tumbuhan yang kurang diketahui secara pasti penyebaran dan kelimpahannya. Telah diperkirakan kurang lebih 253 spesies anggrek endemik, sekitar $80 \%$ dari seluruh jumlah anggrek. Dalam tahap hidup tumbuhan anggrek tropis bersifat epifit, dengan sistem akar menempel pada pohon, namun tidak merugikan pohon inang. Ada yang tumbuh geofitis, dengan istilah lain terresterial artinya tumbuh di tanah dengan akar-akar di dalam tanah. Ada pula yang bersifat saprofit, tumbuh pada media daun-daun kering dan kayu-kayu lapuk yang telah membusuk menjadi humus. Untuk menginventarisasi jenis-jenis angrek hutan di Taman Wisata Alam Batuputih, Kota Bitung, Sulawesi Utara. Penelitian dilaksanakan pada bulan Januari - Februari 2018. Pengambilan data dilakukan dengan metode eksploratif. Jenis-jenis anggrek yang di temukan selama ekplorasi di TWA Batuputih yaitu di urutkan berdasarkan jenis yang paling banyak di temukan pada ketiga transek : yaitu Dendrodium sp dengan jumlah 12 titik yang berada pada ketinggian dari 40-200 mdpl, Phaleonopsis amabilis dengan ketinggian 52-102 mdpl yang berjumlah 3 titik sedangkan, Dendrodium indivisum dengan jumlah 1 titik, yang berada pada ketinggian $136 \mathrm{mdpl}$, Nervilia aragoana sebanyak 10 titik dengan ketinggian 10-84 mdpl, dan Nervilia plicata hanya di temukan 1 titik, pada ketinggian $52 \mathrm{mdpl}$. Dari kelima jenis terdiri dari 3 marga yaitu Dendrodium, Phaleonopsis, dan Nervilia, dan 2 tipe tempat tumbuh (habitat) yaitu teresterial dan epifit.
\end{abstract}

Kata kunci : anggrek, jenis dan habitat anggrek hutan

Eugenia Volume 24 No. 3 Oktober 2018 


\section{PENDAHULUAN}

Tumbuhan anggrek bermanfaat sebagai tanaman hias dan memiliki nilai ekonomi yang tinggi. Anggrek merupakan famili terbesar yang menempati 7-10 \% tumbuhan berbunga dan memiliki sekitar 20.000 sampai 35.000 jenis (Dressler, 1993). Di Sulawesi sendiri, menurut para ahli terdapat sekitar 5000 spesies tumbuhan yang kurang diketahui secara pasti penyebaran dan kelimpahannya. Selain itu, telah diperkirakan kurang lebih 253 spesies anggrek endemik, sekitar $80 \%$ dari seluruh jumlah anggrek, terdapat di Sulawesi (Suhadyah, et al., 2014).

Dalam tahap hidup tumbuhan anggrek tropis bersifat epifit, dengan sistem akar menempel pada pohon, namun tidak merugikan pohon inang. Ada pula yang tumbuh geofitis, dengan istilah lain terresterial artinya tumbuh di tanah dengan akarakar di dalam tanah. Ada pula yang bersifat saprofit, tumbuh pada media daun-daun kering dan kayu-kayu lapuk yang telah membusuk menjadi humus ( Kartikaningrum, dkk., 2004).

Agar keberadaan jenis-jenis anggrek di suatu wilayah dapat diketahui dengan baik, diperlukan suatu penelitian berupa eksplorasi dan inventarisasi. Eksplorasi bertujuan untuk mengambil contoh tanaman yang mempunyai nilai ekonomi dan nilai ilmu pengetahuan yang penting, sedangkan inventarisasi bertujuan untuk mendata keragaman jenis tanaman di suatu kawasan, sehingga apabila nantinya kawasan tersebut mengalami perubahan ekosistem, sudah tersedia data keragaman floranya (Mujahidin, 2002).

Lokasi penelitian, yaitu: Taman Wisata Alam Batuputih yang dahulunya Cagar Alam Gunung Tangkoko. Berdasarkan Surat Keputusan Menteri Pertanian No. 1049 tanggal 21 desember 1981 kawasan seluas $615 \mathrm{Ha}$, ditunjuk sebagai Taman Wisata Batuputih, yang diperuntukan bagi pengembangan wisata alam. TWA Batuputih secara geografis terletak antara 12503'-125015' BT dan 1030'-1034 LU. Secara administratif pemerintahan termasuk Kecamatan Bitung Utara, Kota Bitung, Propinsi Sulawesi Utara. Secara umum kawasan Taman Wisata ini mempunyai topografi dari datar hingga landai (0-35 mdpl) mulai dari hutan pantai dan hutan dataran rendah, berdasarkan Schmidt dan Ferguson CA. Gn. Tangkoko Batuangus mempunyai curah hujan 2.500-3.000 mm/tahun, temperatur rata-rata $20^{\circ} \mathrm{C}$ $25^{\circ} \mathrm{C}$ (MENLHK, 2016).

Untuk mengetahui serta mendeskripsikan kekayaan jenis-jenis angrek hutan di Taman Wisata Alam Batuputih adalah dengan menginventarisasi jenis-jenis dan sebaran anggrek hutan Taman Wisata Alam Batuputih agar data dari hasil penelitian ini bisa dipakai sebagai sumber informasi kekayaan jenis-jenis anggrek serta acuan dalam rangka pengelolaan dan pelestariannya.

Penelitian ini bertujuan untuk menginventarisasi jenis-jenis angrek hutan di Taman Wisata Alam Batuputih. Manfaat yang diharapkan dari penelitian ini adalah sebagai sumber data mengenai kekayaan jenis-jenis tumbuhan anggrek di Taman Wisata Alam Batuputih.

\section{METODE PENELITIAN}

Penelitian dilaksanakan pada bulan Januari - Februari 2018 di Taman Wisata Alam Batuputih.

Bahan yang digunakan dalam penelitian ini adalah buku identifikasi anggrek. Alat-alat yang digunakan adalah peta lokasi, GPS, kamera digital, Binoculer, dan alat tulis.

Penelitian ini dilakukan secara eksploratif dengan menggunakan teknik purposive sampling, yaitu dengan cara menjelajah lokasi penelitian yang telah di tentukan secara sengaja pada kawasan hutan yang ada di Cagar Alam Tangkoko.

Variabel pengamatan meliputi : (1) semua jenis-jenis anggrek (Orchidaceae) berdasarkan tipe habitat dan ketinggian tempat tumbuh; (2) jumlah dan jenis anggrek hutan, dan (3) deskripsi.

\section{Prosedur Kerja}

Pengambilan data dan sampel yaitu menjelajah kasawasan penelitian dari dataran rendah sampai pada dataran tinggi dengan cara zig-zag. Data yang dicatat meliputi, jumlah jenis (difoto dan dikoleksi spesimen hidupnya untuk diidentifikasi), titik koordinat dan ketinggian tempat (menggunakan GPS/ Global Positioning System), morfologi dan habitat. Pada penelitian ini cara purposive sampling 
khusus digunakan dalam proses pengambilan spesimen herbarium, namun semua spesies anggrek yang ditemukan di lapangan akan diidentifikasi. Apabila spesies tersebut sama dengan spesies sebelumnya maka spesies tersebut tidak akan diambil lagi sebagai spesimen. Pengambilan spesimen herbarium dikhususkan pada spesies di lapangan untuk diidentifikasi. Namun apabila terdapat jenis anggrek di lapangan dengan jumlah yang terbatas dan belum diidentifikasi maka spesies anggrek tersebut hanya diambil fotonya saja. Untuk spesies yang dapat diidentifikasi di lapangan maka tidak akan dilakukan pengambilan spesimen untuk herbarium.
Identifikasi tingkat marga berdasarkan pengamatan morfologi tumbuhan anggrek (daun, batang, akar, dan bunga). Untuk identifikasi sampai pada tingkat jenis diperlukan pengamatan morfologi bunganya, apabila jenis yang tidak di jumpai bunganya maka pengamatan hanya sampai pada tingkat marganya.

\section{Analisis Data}

Data dianalisis dengan analisis deskriptif yaitu mendeskripsi jenis-jenis anggrek berdasarkan morfologinya.

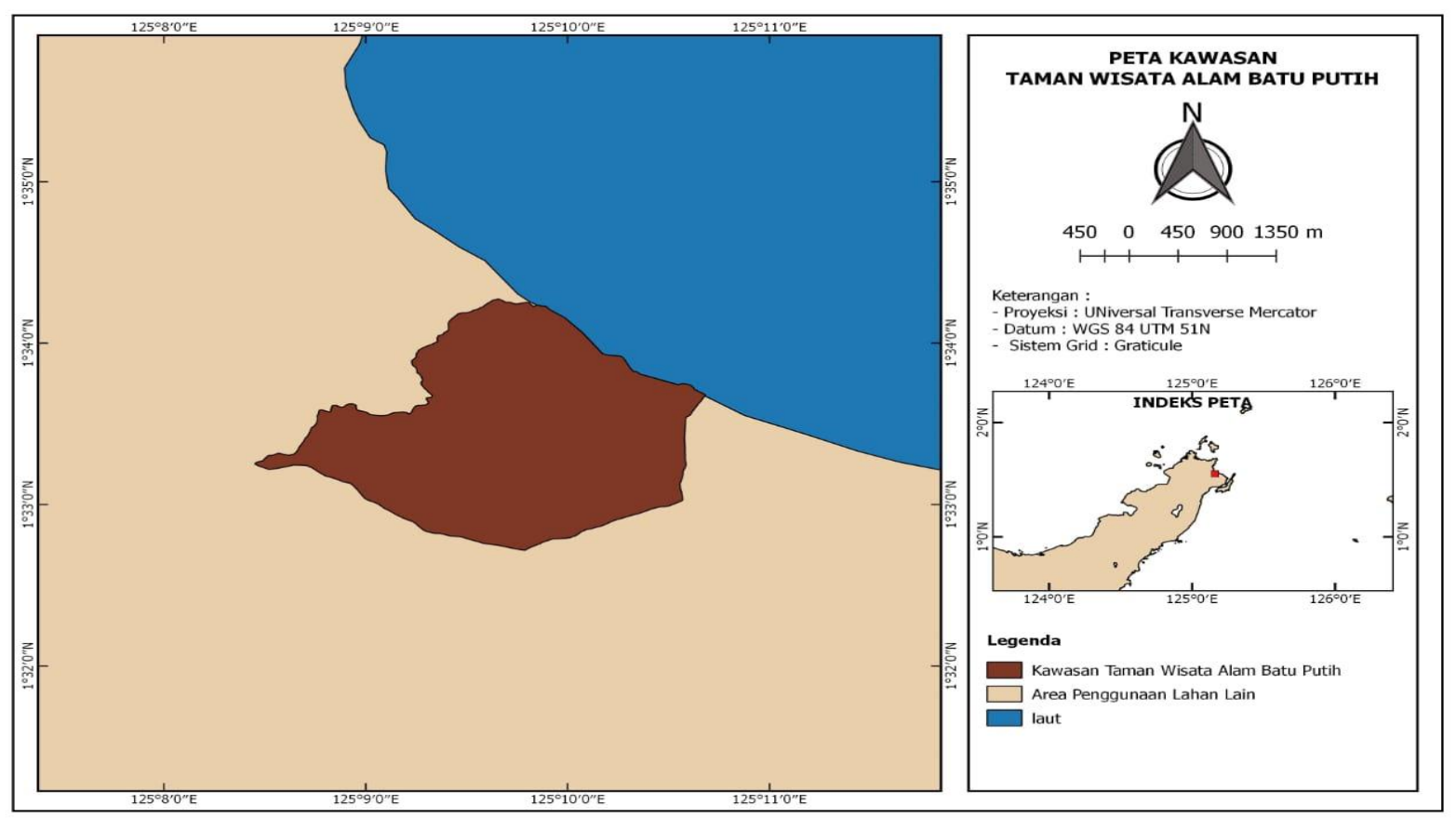

Gambar 1. Peta Kawasan TWA Batuputih

(Figure 1 Map of TWA Batuputih Area)

\section{HASIL DAN PEMBAHASAN}

\section{Daftar Jenis Anggrek Hutan di TWA Batuputih}

Berdasarkan penelitian yang dilakukan di kawasan Taman Wisata Alam Batuputih dapat diketahui jenis keragaman anggrek yang ditemukan sebanyak 3 Marga 5 jenis, tetapi dari 5 jenis yang ditemukan tidak semua dalam fase pembungaan. Jenis-jenis anggrek yang ditemukan selama ekplorasi di TWA Batuputih yaitu di urutkan berdasarkan jenis yang paling banyak ditemukan pada ketiga transek : pada anggrek epifit yaitu
Dendrodium sp dengan jumlah sebanyak 12 titik yang berada pada ketinggian dari 40-200 mdpl, Phaleonopsis amabilis dengan ketinggian 52-102 mdpl yang berjumlah sebanyak 3 titik sedangkan, Dendrodium indivisum dengan jumlah sebanyak 1 titik, yang berada pada ketinggian $136 \mathrm{mdpl}$. Tumbuhan anggrek tipe teresterial yang paling banyak ditemukan yaitu Nervilia aragoana sebanyak 10 titik dengan ketinggian 10-84 mdpl, dan Nervilia plicata hanya di temukan 1 titik, pada ketinggian 52 mdpl. 
Tabel 1 Daftar Jenis-jenis Anggrek Twa Batuputih

(Table 1. List of Orchid TWA Batuputih Types)

\begin{tabular}{clccc}
\hline No. & \multicolumn{1}{c}{ Nama Jenis } & Jumlah & Ketinggian (mdpl) & Habitat \\
\hline 1. & Dendrodium indivisum & 1 & $136 \mathrm{mdpl}$ & Epifit \\
2. & Dendrodium Sp. & 12 & $40-200 \mathrm{mdpl}$ & Epifit \\
3. & Phalenopsis amabilis & 3 & $52-102 \mathrm{mdpl}$ & Epifit \\
4. & Nervilia arogoana & 10 & $10-84 \mathrm{mdpl}$ & Teresterial \\
5. & Nervilia plicata & 1 & $52 \mathrm{mdpl}$ & Teresterial \\
\hline
\end{tabular}

\section{Deskripsi Jenis-Jenis Anggrek Hutan di TWA Batuputih}

Berdasarkan morfologinya yang diamati mulai dari bunga, daun, batang, akar dari hasil eksplorasi jenis-jenis anggrek hutan yang ditemui sebagai berikut :

\section{Nervilia aragoana \\ Klasifikasi}

$\begin{array}{ll}\text { Kingdom } & \text { : Plantae } \\ \text { Devisi } & \text { : Magnoliophyta } \\ \text { Kelas } & \text { : Magnoliopsida } \\ \text { Subkelas } & \text { : Liliideae } \\ \text { Ordo } & \text { : Orchidales } \\ \text { Famili } & \text { : Orchidaceae } \\ \text { Genus } & \text { : Nervilia } \\ \text { Jenis } & \text { : Nervilia aragoana }\end{array}$
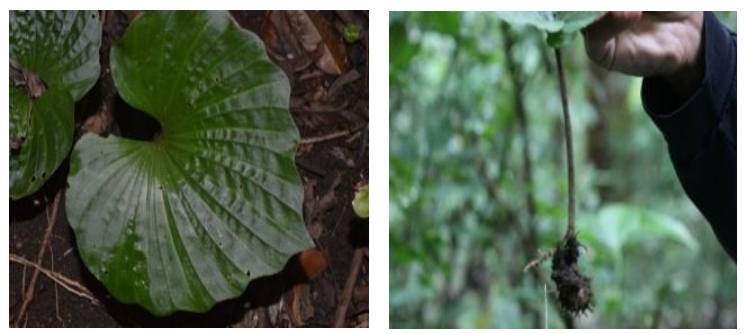

Gambar 2. Nervilia aragoana

(Figure 2. Nervilia aragoana)

\section{Deskripsi}

Nervilia aragoana jenis anggrek teresterial (anggrek tanah), yang dimana habitat hidupnya lebih dari 1 (satu) atau berkelompok. Disaat pengambilan data tidak ditemukan berbunga. Hanya memiliki 1 (daun), bentuk seperti jantung, tepi daun tidak merata atau berombak-ombak, ujung daun meruncing, permukaan daun tidak berbulu, memiliki tulang daun yang melengkung berjumlah 15 , me- miliki batang yang berwarna ungu panjang $13,5 \mathrm{~cm}$, berumbi.

Dari hasil eksplorasi berdasarkan 3 jalur telah ditemukan mulai dari ketinggian 10-84 mdpl dengan kondisi hutan dataran rendah sampai pada hutan sekunder, yang memiliki tutupan tajuk $75 \%$ $95 \%$ serta pada daerah lembab, pada strata 5 (lima) atau tumbuhan lantai.

\begin{tabular}{|c|c|}
\hline \\
\hline \multicolumn{2}{|c|}{$\begin{array}{l}\text { Nervilia plicata } \\
\text { Klasifikasi } \\
\text { Kingdom }\end{array}$} \\
\hline \multicolumn{2}{|r|}{ : Magnoliophyta } \\
\hline \multicolumn{2}{|r|}{ : Magnoliopsida } \\
\hline Subkelas & : Liliideae \\
\hline \multicolumn{2}{|r|}{ : Orchidales } \\
\hline Famili & : Orchidaceae \\
\hline \multicolumn{2}{|r|}{ : Nervilia } \\
\hline \multicolumn{2}{|l|}{ Jenis } \\
\hline
\end{tabular}

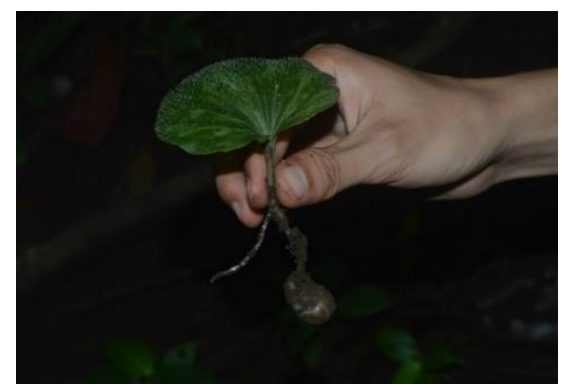

Gambar 3. Nervilia plicata

(Figure 3. Nervilia plicata)

\section{Deskripsi}

Nervilia plicata tumbuhan anggrek tanah, yang berumbi, umbinya membulat seperti telur dengan diameter sekitar $1,8 \mathrm{~cm}$. Daun seperti jantung, dengan jumlah tulang daun 7 , sangat dekat dengan permukaan tanah, permukaan helaian daunnya berbulu, ujung daun tumpul, lebar daun $10-14 \mathrm{~cm}$, batang sekaligus tangkai daun ukuran- 
nya pendek sekitar $1 \mathrm{~cm}$, berwarna hijau kecoklatan gelap, dan hanya memiliki 1 daun. Memiliki akar tunggam.

Berdasarkan data hasil eksplorasi anggrek Nervilia plicata ditemukan pada ketinggian $52 \mathrm{~m}$ Dpl, terdapat pada kondisi hutan sekunder, di daerah lembab, dengan tutupan tajuk $95 \%$, pada strata 5 (lima) atau tumbuhan lantai. Menurut Comber (1990) dalam Puspitaningtyas (2017), Nervilia plicata didistribusikan dari India, Cina, Burma, Laos, Vietnam, Thailand, Jawa, Sumatra, dan Filipina, ke Papua Nugini dan Australia. Spesies ini tumbuh di hutan tropis di bawah teduh pohon di ketinggian 320-450 mdpl.

\section{Dendrodium sp Klasifikasi \\ Kingdom : Plantae \\ Devisi : : : : : \\ Kelas : : Monocotyledoneae \\ Ordo : : Orchidales \\ Suku : Epidendreae \\ Genus : : Dendrodium}

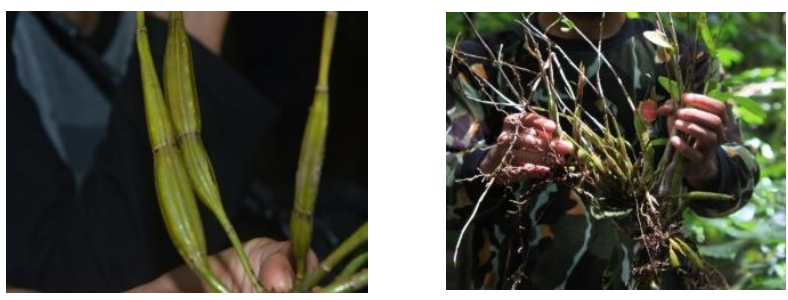

Gambar 4. Dendrodium sp

(Figure 4. Dendrodium sp)

\section{Deskripsi}

Perawakan Dendrobium sp berupa tanaman herba, hidup sebagai epifit. Memiliki sistem perakaran serabut (radix adventicia) dengan rhizome, batangnya besar, berisi cadangan makanan. Bentuknya bulat, arah tumbuh batang tegak lurus dengan sistem percabangan monopodial serta bentuk batang beruas, daunnya tunggal berdaging terdiri dari vagina dan lamina, struktur pertumbuhan daun tidak sejajar/kedudukan daun berseling bergantian, panjang daun 10,8-11,7 cm, lebar 5,6 cm, bentuk daun daun jorong/bujur telur. Batang berumbi. Saat pengamatan tidak ditemukan berbunga.

\begin{tabular}{|c|c|}
\hline \multicolumn{2}{|c|}{ Phaleonopsis amabilis } \\
\hline Kingdom & : Plantae \\
\hline Devisi & : Magnoliophyta \\
\hline Kelas & : Magnoliopsida \\
\hline Subkelas & : Liliideae \\
\hline Ordo & : Orchidales \\
\hline Famili & : Orchidaceae \\
\hline Genus & : Phalaenopsis \\
\hline Jenis & : Phalaenopsis amabilis (L.) B \\
\hline
\end{tabular}

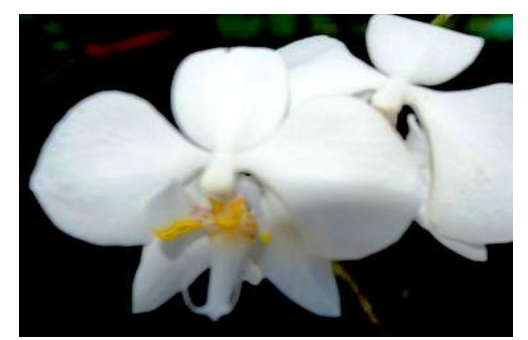

Gambar 5. Bunga Phalaenopsis amabilis

(Figure 5. Bunga Phalaenopsis amabilis

\section{Deskripsi}

Bunganya tumbuh dari ujung batang, bunga majemuk, berwarna putih bersih, berwarna kuning dan bintik kemerahan di bibir bunga. Tangkai bunga memanjang muncul dari ketiak daun. Daun biasanya oval memanjang dengan tulang daun memanjang pula, khas daun monokotil. Daun tebal dengan panjang 20-30 cm dan lebar 5-8 $\mathrm{cm}$. struktur pertumbuhan daun tidak sejajar/ kedudukan daun berseling bergantian. Batangnya tumbuh baik, seringkali menebal dan terlindungi lapisan lilin untuk mencegah penguapan berlebihan. Pertumbuhan batang bersifat memanjang (monopodial) yaitu hanya memiliki satu batang dan satu titik tumbuh saja. Memiliki akar serabut, dan karena Phalaenopsis amabilis jenis epifit yaitu mengembangkan akar sukulen dan melekat pada batang pohon tempatnya tumbuh, namun tidak merugikan pohon inang. Memiliki kelopak bunga (sepal) warnanya mirip mahkota bunga (tepal). Bunga dapat tumbuh hingga diameter $10 \mathrm{~cm}$ lebih. Tidak ditemukan buah pada saat pengambilan data. 


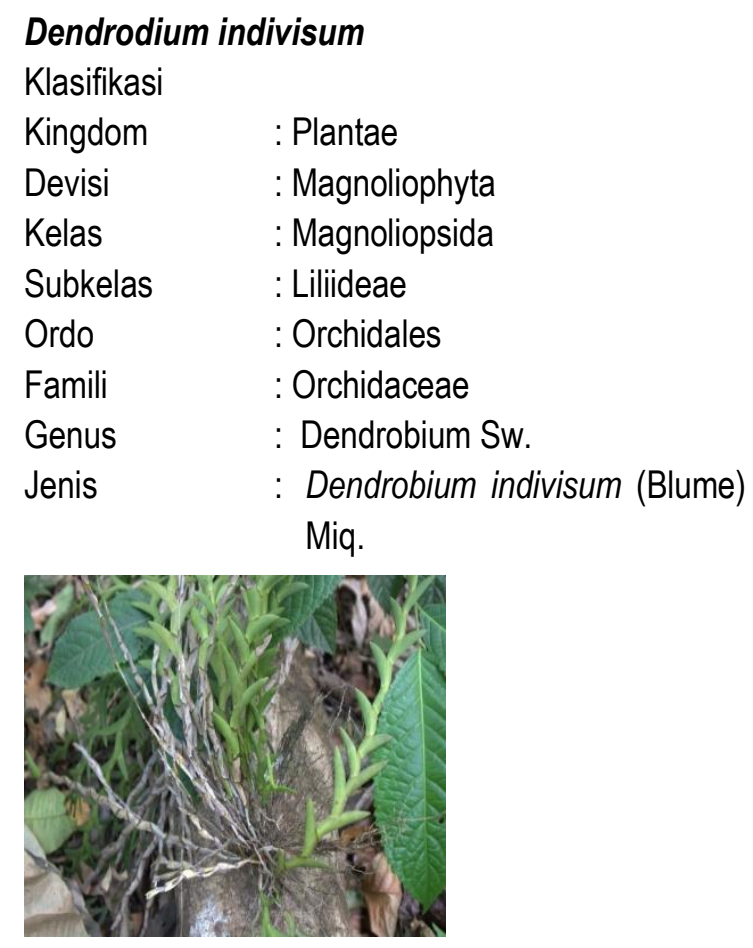

Gambar 6. Dendrodium indivisum

(Figure 6. Dendrodium indivisum)

\section{Deskripsi}

Berdaun tebal dan berdaging, hidup sebagai epefit atau memerlukan tanaman inang, warna daun hijau kekuningan, tidak memiliki tangkai daun, panjang $4 \mathrm{~cm}$, lebar $1,2 \mathrm{~cm}$, bentuk daun lanset, ujung runcing, permukaan kasap, tepi rata, tidak memiliki percabangan, daun berseling dengan ukuran 2-3 mm, tidak memiliki tulang daun. Batang tidak berumbi. Tidak di temukan bunga saat pengambilan data.

\section{Kunci Identifikasi Jenis-jenis Anggrek di TWA}

\section{Batuputih}

1. a. Anggrek hutan teresterial..........................

b. Anggrek hutan epifit.................................3

2. a. Daun: ujung daun meruncing, tidak berbulu, tumbuh berkelompok.............Nervilia aragoana Goudich.

b. Daun: ujung daun tumpul, permukaan daun berbulu, tumbuh individual Nervilia plicata (Andrews) Schltr.

3. a. Pertumbuhan Simpodial.. .4

b. Pertumbuhan monopodial 5
4. a. Daun: panjang $4 \mathrm{~cm}$, lebar $1,2 \mathrm{~cm}$, bentuk daun lanset, tidak memiliki tulang daun. Tidak berumbi semu.

Dendrobium indivisum

b. Daun: panjang $10,8-11,7 \mathrm{~cm}$, lebar 5,6 $\mathrm{cm}$, bentuk daun jorong/bujur telur, ujung daun tumpul, memiliki 1 tulang daun. Berumbi semu

Dendrodium sp

5. Daun: Panjang 20-30 cm, lebar 5-8 cm, bentuk daun jorong. Bunga : berwarna putih, bibir bunga berwarna kuning bintik kemerahan, diameter bunga 6-15 $\mathrm{cm}$

Phaleonopsis amabilis

\section{KESIMPULAN DAN SARAN}

\section{Kesimpulan}

Hasil penelitian yang dilakukan di Taman Wisata Alam Batuputih dari $0 \mathrm{mdpl}-200 \mathrm{mdpl}$ ditemukan anggrek hutan 5 jenis, dari 3 marga yang terdiri dari 2 tipe tempat tumbuh (habitat), yaitu : Teresterial : Nervilia aragoana dan Nervilia plicata, Epifit : Dendrodium sp, Phaleonopsis amabilis dan Dendrodium indivisum.

Saran

Berdasarkan data penelitian ini, maka perlu ada penelitian selanjutnya mengenai jumlah jenis anggek dalam kawasan TWA Batuputih mulai dari 0 mdpl sampai pada ketinggian 1.109 mdpl atau pada daerah puncak yang belum tereksplorasi.

\section{DAFTAR PUSTAKA}

Dressler, R.L. 1993. Phylogeny and Classification of the Orchid family. Portland (OR): Dioscorides press. Melbourne. Australia.

Kartikanungrum, S., D. Widiastoety dan K. Effendie. 2004. Panduan Karakterisasi Tanaman Hias: Anggrek dan Anthurium. Departemen Pertanian Badan Penelitian dan Pengembangan Pertanian Komisi Nasional Plasma Nutfah. Bogor. 
MENLHK. 2016. Informasi 521 Kawasan Konservasi Region Kalimantan-Sulawesi. Bogor.

Mujahidin, S.P., M. Marjuki, D. Supriadi, Rahmat, Atjim dan T. Jodi. 2002. Eksplorasi Anggrek Jawa. Kawasan Taman Nasional Gunung Halimun Banten. Bogor: Pusat Konservasi Tanaman Kebun Raya BogorLIPI.
Puspitaningtyas, D.M. 2017. Orchid Inventory in Bantimurung-Bulusaraung National Park, South Sulawesi, Indonesia. Biodiversitas, 18(1):341-350.

Suhadyah, S., E. Tambaru, R. Sjahril dan M.R. Umar. 2014. Keanekaragaman Anggrek di Hutan Sulawesi Selatan. Prosiding Semnas Biodiversitas, 3(2):127-129. 